\title{
Perceções de alunos do ensino básico sobre a utilização dos jogos na aula
}

\author{
Ana Rita Ferreira ${ }^{a}$, Manuel Vara Pires ${ }^{b}$ \\ ânstituto Politécnico de Bragança, Bragança, Portugal, anaf_rita12@hotmail.com, ${ }^{\mathrm{b}}$ Centro de \\ Investigação em Educação Básica, Instituto Politécnico de Bragança, Campus de Santa Apolónia, \\ 5300-253 Bragança, Portugal, mvp@ipb.pt
}

\begin{abstract}
Resumo
O recurso a jogos pode constituir uma estratégia relevante para a gestão do trabalho em sala de aula, permitindo, aos alunos, oportunidades de aprender melhor, quer na abordagem dos temas disciplinares quer no desenvolvimento de atitudes positivas sobre as suas próprias atuações ou sobre a relação com os outros. Este texto apresenta um estudo exploratório realizado no estágio profissional pela primeira autora, no âmbito de um mestrado para a docência, num contexto de prática de ensino supervisionada em que foi dado destaque ao jogo e ao seu papel nas dinâmicas da aula. O estudo assumiu uma abordagem qualitativa e interpretativa e pretendeu analisar as perceções dos alunos dos anos de escolaridade em que se realizou o estágio profissional - $1 .^{\circ}\left(1 .^{\circ} \mathrm{CEB}\right), 5^{\circ}$ (ciências naturais, 2. $\left.{ }^{\circ} \mathrm{CEB}\right), 6^{\circ}$ (matemática, 2. ${ }^{\circ} \mathrm{CEB}$ ) - sobre o papel dos jogos na sua aprendizagem. As opiniões foram recolhidas através de uma entrevista coletiva no $1 .{ }^{\circ} \mathrm{CEB}$ e de questionários no $2{ }^{\circ} \mathrm{CEB}$, e analisadas recorrendo à análise de conteúdo. Os resultados apontam para perceções favoráveis ao uso dos jogos na aula, por proporcionarem ambientes mais divertidos e estimulantes e ajudarem a aprender melhor os saberes disciplinares e a melhorar as suas atitudes.
\end{abstract}

Palavras-chave: educação básica, jogos, perceções de alunos, ciências naturais, matemática.

\section{Contexto do estudo}

Este texto foca-se num estudo exploratório realizado na Prática de Ensino Supervisionada (PES), correspondente ao estágio profissional para a docência do Mestrado em ensino do $1 .^{\circ}$ ciclo do ensino básico (CEB) e de matemática e ciências naturais no 2. ${ }^{\circ} \mathrm{CEB}$. As práticas de ensino realizadas assumiram o uso dos jogos em sala de aula como o seu tema integrador e foram desenvolvidas numa turma do $1 .^{\circ} \mathrm{CEB}$ ( $1 .^{\circ}$ ano de escolaridade), assegurando todas as áreas disciplinares - Português, Estudo do Meio, Matemática e Expressões, e em duas turmas do $2 .^{\circ} \mathrm{CEB}\left(5 .^{\circ}\right.$ ano em Ciências Naturais e $6 .^{\circ}$ ano em 
Matemática). Essa assunção suporta-se no grande reconhecimento de que tarefas que apelem a características associadas ao jogo podem ajudar a melhorar, entre outros aspetos, a capacidade dos alunos de questionar, de relacionar ou de respeitar e aceitar melhor as opiniões dos outros colegas, podendo potenciar aprendizagens mais significativas e consolidadas (Alves \& Oliveira, 2016; Moreira \& Oliveira, 2004). Neste sentido, o recurso a jogos na abordagem dos temas pode ser uma boa alternativa para incrementar, entre outros aspetos, a motivação dos alunos e a sua vontade de aprender (Grando, 2000).

Em diversas aulas, ao longo do ano letivo, os alunos tiveram a oportunidade de trabalhar conteúdos curriculares através de diferentes jogos, quer adaptados de jogos populares entre eles quer concebidos especificamente para a exploração de um determinado tema. Dadas as suas características, o jogo Quizz: quem sou eu? foi adaptado a vários temas e situações e usado nos três anos de escolaridade. Para além deste, os alunos exploraram outros jogos, de que são exemplo: (i) $1 .^{\circ}$ ano: Jogo das vogais, Jogo das sílabas, Bingo matemático, Jogo da mímica; (ii) 5. ${ }^{\circ}$ ano: Jogo da memória do microscópio, Jogo da forca em ciências; e (iii) $6 .^{\circ}$ ano: Jogo da glória das isometrias, Quem quer ser sabichão, SuperT de OTD. Aspetos mais detalhados sobre a utilização e o aproveitamento de alguns destes jogos podem ser vistos nas experiências de ensino e aprendizagem apresentadas e discutidas em Ferreira (2019).

\section{O jogo em contexto de sala de aula}

Há uma grande diversidade de jogos. Há jogos que dependem essencialmente da sorte ou do acaso. Há outros jogos que não dependem só do acaso, mas também das decisões que o jogador vai tomando. Veja-se o exemplo dos jogos de cartas em que o acaso apenas se verifica no momento em que as cartas são distribuídas pelos jogadores, já que o resto do jogo depende das estratégias que os jogadores seguem e das decisões que vão tomando.

Muitos estudos e recomendações têm destacado a importância da utilização dos jogos em ambiente escolar (Alves \& Bianchin, 2010; Associação de Professores de Matemática [APM], 2009; Batista \& Dias, 2012; Costa, 2012; Moreira \& Oliveira, 2004). Uma das características realçadas e muito comum nesses trabalhos é a "existência de regras", uma vez que estas "têm como finalidade organizar algo que, de outro modo, entregue apenas ao acaso, construiria o caos" (Barbeiro, citado por Cabral, 2012, p. 64). Como o jogo é regido por regras, os alunos devem aprendê-las e inteirarem-se delas antes de começarem a jogar. Este aspeto é fundamental no processo de aprendizagem, pois os alunos aprendem a aceitar o facto de se regerem por determinadas regras, como acontece quando vivem em sociedade.

Os jogos constituem, então, recursos pedagógicos a que o professor pode recorrer nas suas aulas (APM, 2009; National Council of Teachers of Mathematics [NCTM], 2017) no sentido de potenciar o desenvolvimento cognitivo e socioafetivo dos alunos (Hohmann \& Weikart, 2011; Moreira \& Oliveira, 2004) dado que, quando jogam, "aprendem e 
apreendem o mundo, experimentam diferentes habilidades motoras, cognitivas e sociais, reproduzem e recriam situações do quotidiano, desenvolvem a cooperação, aprendem a lidar com situações de conflitos" (Condessa, 2009, p. 109). Por possibilitarem entretenimento (Alves \& Oliveira, 2016), os jogos despertam a atenção dos alunos devido ao seu "carácter prazeroso e estimulante" (Costa, 2012) e podem permitir aprendizagens com prazer e promover a criatividade com diversão (Garcia \& Marques, 2001).

Nesta perspetiva, os jogos também devem ser desafiantes para os alunos de forma a que, enquanto se realizam, criem uma competição saudável e captem a sua atenção enquanto desenvolvem as tarefas. Como referem Moreira e Oliveira (2004), os jogos, permitindo aprender de uma forma divertida e dinâmica, podem ajudar a centrar a atenção dos alunos em relação a conteúdos que muitas vezes seriam de difícil abordagem e compreensão. Mas, igualmente, os jogos, naturalmente competitivos, também podem desviar a atenção dos alunos do ponto principal, que é aprender e consolidar conhecimentos.

Em contexto de sala de aula, os jogos devem ser utilizados sempre com uma intencionalidade educativa para que os alunos lhes possam atribuir significado e integrá-los nas suas aprendizagens. O recurso a um jogo pode ser uma opção do professor em diferentes situações, como a introdução, a exploração ou a sistematização de um determinado conceito ou procedimento disciplinar. Mas a atividade a desenvolver deve concretizar momentos de discussão sobre as ações desencadeadas, fazendo emergir outras formas de raciocínio ou estratégias de resolução das tarefas (Grando, 2000), dando mais sentido ao trabalho realizado na sala de aula.

Para além do reconhecimento da importância dos jogos, muito trabalhos têm sido conduzidos no sentido de destacar situações vantajosas. Alves e Oliveira (2016) consideram que a utilização dos jogos na sala de aula, "numa perspetiva de resolução de problemas, garante ao processo educativo os aspetos que envolvem a exploração, explicitação, aplicação e transposição para novas situações-problema do conceito vivenciado" (p. 4). Para Grando (2000), um determinado jogo pode ser muito útil como recurso facilitador da aprendizagem de conceitos e procedimentos, mas, para que o seu uso seja produtivo, é necessário ter em conta aspetos como: (i) o jogo ser interessante e desafiador; (ii) permitir que o aluno consiga avaliar o seu desempenho ao longo do jogo; (iii) contabilizar o tempo de jogo; e (iv) assegurar a participação de todos os jogadores.

Assim, apesar das diversas vantagens da concretização de um jogo em sala de aula, é igualmente importante estar atento às desvantagens que podem emergir durante a sua realização, bem como as relacionadas com a forma como o jogo é aplicado. Grando (2000) apresenta uma sistematização de vantagens e desvantagens da utilização do jogo em sala de aula. Na perspetiva dos alunos, a autora adianta, como vantagens, o desenvolvimento "da criatividade, do senso crítico, da participação, da competição "sadia", (...) do prazer em 
aprender" e "a conscientização do trabalho em equipe", a "significação para conceitos aparentemente incompreensíveis" ou "aprender a tomar decisões e saber avaliá-las" (p. 35). Como desvantagens, realça a "perda da "ludicidade" do jogo pela "interferência constante do professor, destruindo a essência do jogo", a possibilidade de os alunos "jogarem e se sentirem motivados apenas pelo jogo, sem saber porque jogam" ou exigir que joguem, mesmo não querendo, “destruindo a voluntariedade pertencente à natureza do jogo" (p. 35).

\section{Opções metodológicas}

O trabalho desenvolvido ao longo da PES, focado no uso de jogos na sala de aula, foi orientado para a questão-problema "Qual o papel que o jogo desempenha no processo de ensino e aprendizagem?", no sentido de identificar processos seguidos na realização dos jogos e de analisar perceções de alunos e professores sobre a sua utilização $O$ estudo exploratório, que se apresenta, corresponde a uma parte desse trabalho, pretendendo concretizar o objetivo "analisar perceções dos alunos sobre a utilização dos jogos na sua aprendizagem”. Para isso, assumiu uma abordagem qualitativa e interpretativa (Amado, 2014; Bogdan \& Biklen, 2013), procurando interpretar uma dada situação e investigar significados nas ações dos intervenientes e nas suas interações (Coutinho, 2015).

Os dados foram recolhidos através de uma entrevista coletiva, registada em áudio, com os onze alunos do $1 .^{\circ}$ ano do $1 .^{\circ} \mathrm{CEB}$ que mostraram disponibilidade para o estudo e de um questionário respondido por trinta e seis alunos do $2 .^{\circ} \mathrm{CEB}$ (dezoito do $5 .^{\circ}$ ano em Ciências Naturais e dezoito do $6 .^{\circ}$ ano em Matemática). A entrevista foi realizada no final da intervenção educativa na turma e orientada por quatro perguntas globais: [P1] De todos os jogos que realizamos, qual foi o que mais gostaram? Porquê?; [P2] O que é que aprenderam com os jogos realizados em aula? Porquê?; [P3] Que conteúdos aprenderam com o jogo? Porquê?; e [P4] Gostam mais das aulas com jogos ou sem jogos? Porquê?. O questionário foi concretizado no final do ano letivo e organizado em seis questões: [Q1] Quando se fala em jogo, qual é o primeiro jogo que realizamos que te vem à memória? Indica duas razões para essa preferência.; [Q2] Consideras que os jogos realizados foram fundamentais para a aprendizagem? Porquê?; [Q3] Os jogos motivam a aprendizagem e promovem o interesse pelos conteúdos?; [Q4] Qual foi o jogo que mais te motivou a aprender? Porquê?; [Q5] O que achas que contribuiu mais para a aprendizagem? Porquê?; e [Q6] Achas que o jogo deveria ser utilizado mais vezes nas aulas? Porquê?.

A análise dos dados recorreu a aspetos da análise de conteúdo (Amado, 2014; Bardin, 2013), no sentido de os categorizar e classificar. Cada resposta foi analisada e dividida em várias unidades que exprimissem uma única ideia, de modo a enquadrar as opiniões dos alunos em categorias. Também foi quantificado o número de respostas por categoria e feita a apresentação dos resultados em tabelas de frequências. 


\section{Perceções dos alunos sobre o uso de jogos}

Nesta secção, apresentam-se alguns resultados representativos das perceções dos alunos mais focadas e orientadas para a explicitação das aprendizagens que, nas suas perspetivas, foram realizadas.

Os alunos do $1 .^{\circ} \mathrm{CEB}$, na preferência por um dado jogo, atenderam à sua natureza (se é jogado individualmente ou por equipas), às regras e ao divertimento que proporcionou, mas também a relacionaram a questões ligadas às aprendizagens, sabendo explicitar, em alguns casos, as aprendizagens que conseguem realizar. Os alunos reconheceram que os jogos ajudaram a aprender melhor os temas disciplinares e a desenvolver aspetos afetivos, como o respeito pelos outros, considerando-os benéficos para as suas aprendizagens.

[P1] Preferências referidas: (i) "Jogo do bingo" (3 referências), porque "jogávamos sozinhos e só dois é que fizeram bingo e ganharam" (Aluno 6 (A6)), "não era em equipas e aprendemos melhor as contas de "menos" [subtração] e de "mais" [adição]" (A3) e "por não ser em equipas" (A1): (ii) "Jogo da mímica" (2 referências), porque "rebentávamos os balões e imitávamos as palavras que lá estavam e, pronto, gostei mais desse jogo, porque gosto dos balões e foi divertido" (A5) e "gostei de rebentar os balões, tirar o papel e imitar para os outros acertarem" (A2); "Jogo das vogais" (1 referência), dado que "gosto de aprender e saber as letras", reconhecendo que "assim aprendi melhor" (A5).

[P2] Aprendizagens referenciadas: (i) a leitura, a escrita, os números e as operações (3 referências), "aprendi a fazer melhor as contas e a ler melhor" (A2) ou "aprendi a fazer melhor as contas, a escrever" (A7); (ii) aprendizagens gerais (2 referências), "aprendi coisas novas, coisas diferentes que nunca tínhamos aprendido" (A6): (iii) atitudes (2 referências), "aprendi (...) a saber respeitar os meus colegas" (A7); e (iv) os próprios jogos (3 referências), "aprendi a jogar" (A3) ou "os jogos podem fazer com que nós aprendamos e saibamos mais" (A4).

Os alunos do 2. ${ }^{\circ}$ CEB consideraram, globalmente, que a utilização dos jogos em contexto educativo é importante para as suas aprendizagens, tanto para trabalhar os conteúdos disciplinares como para trabalhar atitudes e aspetos afetivos, como a relação entre eles, respeitando os colegas de grupo e da turma.

Todos os alunos que responderam à questão 2 [Q2] consideraram os jogos fundamentais para as suas aprendizagem. As razões adiantadas para suportar as suas opiniões remeteram quer para aspetos mais relacionados com os saberes disciplinares quer para aspetos de natureza mais afetiva, conforme se pode observar nas Tabela 1.

Em Ciências Naturais, a maioria dos alunos (65\%) realçou o facto de aprenderem "coisas diferentes" ou "com divertimento". estes alunos também referiram a ajuda a "relembrar os conteúdos" trabalhados em aula (11\%), a "estar com mais atenção" (6\%) e a aprender com mais facilidade $(6 \%)$, bem como a "despertar o interesse" (6\%). Em Matemática, "aprender 
e trabalhar melhor os conteúdos" foi, claramente, a razão mais referida (61\%), havendo ainda algum destaque para "trabalhar de forma divertida" (17\%) e "aprender enquanto jogamos" (10\%).

Tabela 1: Razões para os jogos serem fundamentais para a aprendizagem.

\begin{tabular}{|c|c|c|}
\hline Jogos fundamentais para a aprendizagem para... & referências (n. ${ }^{\mathbf{}}$ ) & referências (\%) \\
\hline Ciências Naturais & & $(100 \%)$ \\
\hline Aprender coisas diferentes & $(18)$ & 38 \\
\hline Aprender com divertimento & 5 & 27 \\
\hline Ajudar a relembrar os conteúdos & 2 & 11 \\
\hline Ser mais fácil aprender & 1 & 6 \\
\hline Ajudar a estar com mais atenção & 1 & 6 \\
\hline Despertar o interesse & 1 & 6 \\
\hline (ausência de resposta) & 1 & 6 \\
\hline & & $(100 \%)$ \\
\hline Matemática & $(18)$ & 61 \\
\hline Aprender e trabalhar melhor os conteúdos & 11 & 17 \\
\hline Trabalhar de forma divertida & 3 & 10 \\
\hline Aprender enquanto jogamos & 2 & 6 \\
\hline Ser uma forma mais fácil e prática de aprender & 1 & 6 \\
\hline Melhorar os resultados em Matemática & 1 & \\
\hline
\end{tabular}

Fonte: Ferreira (2019).

Concretizando estas ideias, os alunos exprimiram as suas opiniões sobre o que, numa situação de uso de jogos, mais contribuiu para a aprendizagem [Q5]. Na Tabela 2, apresenta-se a categorização resultante das opiniões expressas pelos alunos.

Tabela 2: $\mathrm{O}$ que contribuiu mais para a aprendizagem.

\begin{tabular}{|c|c|c|}
\hline O que contribuiu mais para a aprendizagem & $\mathbf{n .}^{\mathbf{0}}$ de referências & \% de referências \\
\hline Ciências Naturais & & \\
\hline Estar atento durante o jogo & $(18)$ & $(100 \%)$ \\
\hline Serem divertidos & 9 & 50 \\
\hline Serem jogos educativos & 2 & 10 \\
\hline Jogar em grupo & 1 & 6 \\
\hline Relembrar os conteúdos & 1 & 6 \\
\hline (ausência de resposta) & 1 & 6 \\
\hline & 4 & 22 \\
\hline Matemática & & $(100 \%)$ \\
\hline Ser um jogo & $(18)$ & 28 \\
\hline Permitir que aprenda mais e melhor & 5 & 22 \\
\hline Ser divertido & 4 & 16 \\
\hline Jogar em grupo & 3 & 16 \\
\hline Ser motivador & 3 & 6 \\
\hline Aprender a respeitar a opinião dos outros & 1 & 6 \\
\hline (ausência de resposta) & 1 & \\
\hline
\end{tabular}

Fonte: Ferreira (2019). 
Como se pode observar, os alunos indicaram aspetos diversificados. Em Ciências Naturais, metade dos alunos (50\%) respondeu que o que mais contribuiu para a aprendizagem em situações de jogo foi a "atenção durante o jogo". As restantes cinco referências (quatro alunos não registaram qualquer razão) focaram-se em "os jogos serem divertidos" (10\%) e "serem jogos educativos", "jogados em grupo" e permitirem "relembrar os conteúdos", cada uma com 6\%. Já em Matemática, o facto de "ser um jogo" foi o aspeto mais referido (28\%), mas potenciar a aprendizagem (22\%), "ser divertido" (16\%) e "ser jogado em grupo" (16\%) também foram aspetos destacados.

\section{A concluir}

Globalmente, os alunos revelaram perceções muito favoráveis sobre a utilização dos jogos na sala de aula, considerando que ajudam nas aprendizagens que realizam (Grando, 2000), proporcionando ambientes de trabalho mais divertidos e estimulantes (APM, 2009; Costa, 2012; NCTM, 2017).

Por isso, os alunos referiram que os jogos devem ser utilizados mais vezes na aula, dado que permitem compreender melhor os conteúdos trabalhados e melhorar as atitudes (Condessa, 2009; Grando, 2000), como saber trabalhar em grupo ou respeitar as opiniões dos colegas (Moreira \& Oliveira, 2004). O facto de os jogos realizados nas aulas serem jogados em grupo foi valorizado por muitos alunos, pois ajudam a aprender a respeitar os colegas e as suas opiniões. Como salientam Alonso e Roldão (2005), o facto de trabalharem em grupo proporciona-lhes a oportunidade de partilhar saberes e atitudes, o que permite que a aprendizagem através do jogo seja muito mais rica e significativa.

Os alunos consideraram, ainda, que os jogos são uma forma diferente de trabalhar os conteúdos e que proporcionam uma forma diferente de compreensão dos mesmos (Moreira \& Oliveira, 2004). Alguns alunos afirmaram que apenas compreenderam determinados conteúdos no momento em que os trabalharam através do jogo.

A concluir, estamos convictos que os jogos podem ser valiosos auxiliares do processo de ensino e aprendizagem, potenciando o desenvolvimento cognitivo e social. Ao cativarem a atenção dos alunos, despertarem a sua curiosidade, ao mesmo tempo que criam fantasia e desafio, os jogos auxiliam na aprendizagem, nomeadamente dos conceitos mais complexos e abstratos, mas também no desenvolvimento dos conhecimentos e competências mais elaborados. Todas estas características estimulam a aprendizagem por descoberta e a "aprender a aprender". 


\section{Referências}

Alonso, L., \& Roldão, M. C. (2005). Ser professor do $1 .{ }^{\circ}$ ciclo: Construindo a profissão. Coimbra: Edições Almedina.

Alves, L., \& Bianchin, M. (2010). O jogo como recurso de aprendizagem. Revista Psicopedagogia, $27(83)$.

Alves, T., \& Oliveira, G. (2016). O uso de jogos na sala de aula de matemática: Uma proposta com o bingo dos números inteiros. In Anais do III CONEDU, Congresso Nacional de Educação. Disponível em https://www.editorarealize.com.br/revistas/conedu/anais.php

Amado, J. (Ed.) (2014). Manual de investigação qualitativa em educação. Coimbra: Universidade de Coimbra.

Associação de Professores de Matemática. (2009). Renovação do currículo de matemática. Seminário de Vila Nova de Milfontes - 1988. Lisboa: Associação de Professores de Matemática.

Bardin, L. (2013). Análise de conteúdo. Lisboa: Edições 70.

Batista, D., \& Dias, C. (2012). O processo de ensino e de aprendizagem através dos jogos educativos no ensino fundamental. Colloquium humanarum, 9 (n. ${ }^{\circ}$ especial).

Bogdan, R., \& Biklen, S. (2013). Investigação qualitativa em educação: Uma introdução à teoria e aos métodos. Porto: Porto Editora.

Cabral, M. (2012). Práticas educativas e jogo como instrumento de aprendizagem no pré-escolar e no $1 .{ }^{\circ}$ ciclo do ensino básico. Relatório final de estágio, Universidade dos Açores, Ponta Delgada, Portugal.

Condessa, I. (2009). (Re)aprender a brincar. Ponta Delgada: Nova Gráfica, Lda.

Costa, C. (2012). A importância do jogo no processo de ensino e aprendizagem de alunos com perturbação de hiperatividade e défice de atenção. Relatório final de estágio, Escola Superior de Educação João de Deus, Lisboa, Portugal.

Coutinho, C. (2015). Metodologia de investigação em ciências sociais e humanas: Teoria e prática (2. ${ }^{\mathrm{a}}$ ed.). Coimbra: Almedina.

Ferreira, A. R. (2019). Prática de Ensino Supervisionada: O uso de jogos no ensino e aprendizagem na educação básica. Relatório final de estágio, Instituto Politécnico de Bragança, Bragança, Portugal. Disponível em http://hdl.handle.net/10198/20556

Garcia, R., \& Marques, L. (2001). Aprendendo a brincar. Porto Alegre: Novak Multimídia.

Grando, R. C. (2000). O conhecimento matemático e o uso de jogos na sala de aula. Tese de doutoramento, Universidade Estadual de Campinas, Campinas, Brasil.

Hohmann, M., \& Weikart, D. (2011). Educar a criança. Lisboa: Fundação Calouste Gulbenkian.

Moreira, D., \& Oliveira, I. (2004). O jogo e a matemática. Lisboa: Universidade Aberta.

National Council of Teachers of Mathematics. (2017). Princípios para a ação: Assegurar a todos o sucesso em matemática. Lisboa: Associação de Professores de Matemática. 